\title{
TIPE GROUP INVESTIGATION (GI) PADA MATERI MAKRO MOLEKUL (POLIMER)
}

\author{
Roma Mindo Siregar (romamindo123@gmail.com) \\ SMA KATOLIK SIBOLGA
}

\begin{abstract}
ABSTRAK
This study aims to determine whether there is a relationship between the Group Investigation (GI) type learning model towards learning motivation and chemistry learning outcomes in polymeric materials. The research method used is quantitative research that is correlational. Sampling in this study was students of class XII IPA Catholic High School Sibolga. The results of this study are that there is a significant relationship between the learning model of the Group Investigation (GI) type and the learning outcomes of chemistry in the polymeric material of class XII IPA students at Sibolga Catholic High School at 0.316 with a low category.
\end{abstract}

Keywords: Type of Group Investigation (GI), Polymer

\begin{abstract}
ABSTRAK
Penelitian ini bertujuan untuk mengetahui adakah hubungan model pembelajaran tipe Group Investigation (GI) terhadap motivasi belajar dan hasil belajar kimia pada materi polimer. Metode penelitian yang dilakukan adalah penelitian kuantitatif bersifat korelasional. Pengambilan sampel dalam penelitian ini yaitu peserta didik kelas XII IPA SMA Katolik Sibolga. Hasil penelitian ini adalah ada hubungan yang signifikan antara model pembelajaran tipe Group Investigation (GI) dengan hasil belajar kimia pada materi polimer peserta didik kelas XII IPA SMA Katolik Sibolga sebesar 0,316 dengan kategori rendah.
\end{abstract}

Kata Kunci: Tipe Group Investigation (GI), Polimer

\section{PENDAHULUAN}

Tujuan Pendidikan Nasional adalah berkembangnya potensi peserta didik agar menjadi manusia-manusia yang: beriman dan bertakwa kepada Tuhan Yang Maha Esa, berakhlak, sehat, berilmu, cakap, kreatif, mandiri, dan menjadi warga Negara yang demokratis serta bertanggung jawab. (UU nomor 20 tahun 2003; PP nomor 19 tahun 2005)
Pendidikan adalah usaha sadar untuk menumbuh kembangkan potensi Sumber Daya Manusia (SDM) secara utuh melalui kegiatan pengajaran yang penekanan pada tiga aspek penting yaitu ranah kognitif, afektif dan psikomotorik. Oleh sebab itu pemerintah telah berupaya untuk meningkatkan mutu pendidikan dengan mengeluarkan peraturan perundang-undangan yang berlaku kemudian diturunkan lagi dalam berbagai Peraturan Menteri Pendidikan 
Nasional.Namun

apakah

memperbaiki mutu

didaerahnya.

Oleh karena itu suatu lembaga pendidikan mempunyai beban ganda yaitu melestarikan nilai-nilai budaya tradisional dan juga mempersiapkan generasi muda agar dapat menyiapkan diri menghadapi tantangan kemajuan jaman yang semakin kompleks dalam memasuki era globalisasi.

Guru juga dituntut mencermati perkembangan media, tehnologi, yang digunakan oleh sekolah untuk menemukan berbagai metode mengajar yang tepat. Berdasarkan perkembangan jaman era tehnologi dan informasi sudah menjadi kewajiban bagi guru dan peserta didik untuk menggali informasi melalui media dan fasilitas lainnya.

Sekolah dan pemerintah juga perlu menyediakan sarana pendidikan yang memadai untuk menyediakan daya dukung pembelajaran sehingga dapat menekan permasalahan yang muncul ketika out put peserta didik dari sekolah apakah mampu bersaing dengan dunia pendidikan lainnya atau memasuki seleksi ke sekolah menengah umum atau sekolah kejuruan yang sangat ketat dan selektif.

Berdasarkan perkembangan memasuki implementasi kurikulum 2013 sudah saatnya sebagai pendidik yang profesional harus merubah paradigma lama atau model pembelajaran konvensional yaitu peserta didik hanya sebagai penerima informasi pengetahuan, dan pendidik tidak hanya ibarat mengisi gelas kosong, sebagai target memenuhi kewajiban pengajaran. Melainkan harus merubah dengan paradigma baru yaitu sistem pembelajaran harus berpusat pada peserta didik yang aktif mencari informasi, dan sebagai pendidik lebih memberikan ransangan agar peserta didik menjadi pebelajar yang aktif. Pembelajaran di sekolah perlu penerapan konsep-konsep dalam pembelajaran yang diperkaya dengan keadaan dan kebutuhan perkembangan peserta didiknya. Dalam penelitian ini peneliti memfokuskan pada materi polimer dengan menggunakan model kooperatif tipe group investigation (GI).

Pemanfaatan lingkungan sebagai sumber belajar yang diangkat dalam penelitian ini berhubungan dengan polimer dan limbahnya di sekolah, dimana peserta didik dapat menjawab permasalahan yang dijumpai dalam kehidupan sehari-hari sebagai wujud penerapan dari model pembelajaran yang berbasis pada lingkungan dan peserta didik dapat berkarya, berinovatif sebagai wujud dari penanaman sikap kepedulian terhadap lingkungan, dan bagaimana mengatasi limbah polimer itu sendiri. 
Sekolah Menengah Atas (SMA)

Katolik Sibolga dalam rapat dewan guru dan kepala sekolah yaitu mengapa peserta didik tidak mengalami ketuntasan belajar polimer mata pelajaran kimia. Masalah belajar memang sangat kompleks terutama dari kebiasaan guru mengajar yang cenderung menggunakan model pembelajaran yang konvensional berdasarkan hasil observasi bahwa pelajaran nilai rat-rata untuk mempelajari kimia pada materi polimer peserta didik. Oleh karena itu, peneliti berusaha mencari jawaban untuk mengatasi masalah belajar kimia dengan menggunakan model pembelajaran tipe group investigation.

\section{METODE PENELITIAN}

Penelitian yang dilakukan adalah bersifat korelasional dimana ada keterkaitan antara variablevariabel.Variabel bebas (Variabel independen) dan variable terikat (variabel dependen). Model pembelajaran kooperatid tipe group investigation merupakan variabel bebas (X). Variabel terikat adalah hasil belajar (Y).

Populasi yang diambil dalam penelitian ini yaitu kelas XII IPA diperlakukan materi yang sama yang digunakan untuk menguji setiap instrument penilaian, baik uji validitas,
Uji reliabilitas. Sedangkan kelas XII IPA 342 orang. sebagai kelas eksperimen dengan menggunakan pembelajaran kooperatif tipe group investigation. Peserta didik kelas XII IPA 1.39 orang, sebagai kelas Kontrol dengan menggunakan model pembelajaran secara konvensional.

Dalam penelitian ini jenis angket yang digunakan adalah angket tertutup karena sudah disediakan jawaban pada angket dan peserta didik memilih salah satu dari jawaban yang disediakan yaitu pernyataan Sangat setuju (SS), Setuju (S), Tidak setuju (TS), dan Sangat tidak setuju (STS). Pengujian angket dengan menggunakan Validitas konstrak (construct validity). Pengujian Reliabilitas instrument dengan rumus Alfa Crombach yaitu digunakan untuk menguji reliabilitas instrument skala likert (1 sampai 4 ).

Analisis Hipotesis

Menurut Duwi Priyatno (2011:34), “ Analisis korelasi Pearson atau Product Moment Pearson adalah analisis untuk mengetahui keeratan hubungan antara dua variabel dan untuk mengetahui arah hubungan yang terjadi untuk data berskala interval atau rasio. Nilai korelasi (r) berkisar antara 1 sampai -1 , nilai semakin mendekati 1 atau -1 berarti hubungan antara dua variable semakin kuat, sebaliknya nilai 
mendekati 0 berarti hubungan antara dua variabel semakin lemah. Koefisien korelasi dapat digambarkan pada tabel 2.

Tabel. 2. Interpretasi koefisienkoelasi

\begin{tabular}{|l|l|}
\hline Korelasi & Hubungan \\
\hline $0,00-0,199$ & Sangat rendah \\
\hline $0,20-0,399$ & Rendah \\
\hline $0,40-0,599$ & Sedang \\
\hline $0,60-0,799$ & Kuat \\
\hline $0,80-1,000$ & Sangat Kuat \\
\hline
\end{tabular}

(Sugiyono, 2013).

Hasil analisis n-Gain.

n-Gain dilakukan untuk mengetahui peningkatan pemahaman konsep peserta didik setelah pembelajaran yang dilakukan oleh
peneliti.n-Gain yang digunakan disini untuk mengukur peningkatan hasil belajar peserta didik pada kelas eksperimen dan kelas control. Krieria nGain yang digunakan dapat dilihat pada tabel .3.

Tabel.3. Kriteria n-Gain

\begin{tabular}{|l|l|}
\hline \multicolumn{1}{|c|}{ TINGKAT } & \multicolumn{1}{c|}{ NILAI N-GAIN } \\
\hline Tinggi & $\geq 0,7$ \\
\hline Sedang & $0,3 \geq$ n-Gain $<0,7$ \\
\hline Rendah & $<0,3$ \\
\hline
\end{tabular}

Sumber : (Hake, 1998).

\section{HASIL DAN PEMBAHASAN}

Hasil uji n-Gain rata-rata untuk setiap RPP dapat dirampungkan kedalam tabel 3.dan 4.

Tabel 3. Perbedaan rata-rata tingkat pemahaman

konsep peserta didik disetiap RPP.

\begin{tabular}{|c|c|c|c|c|c|c|c|c|}
\hline RPP & $\begin{array}{l}\text { n-GAIN } \\
\text { rata-rata }\end{array}$ & $\mathrm{N}$ & Mean & $\begin{array}{l}\text { Std. } \\
\text { Deviation }\end{array}$ & Positive & Negative & $\begin{array}{l}\text { Kolmogorof } \\
\text { Smirnov Z }\end{array}$ & $\begin{array}{l}\text { Sig.(2- } \\
\text { tailed) }\end{array}$ \\
\hline \multirow{2}{*}{1} & $\begin{array}{l}\text { n-G1. } \\
\text { Eksperimen }\end{array}$ & \multirow{6}{*}{30} & 0,3933 & 0,28082 & 0,177 & 0,290 & 1,587 & 0,13 \\
\hline & $\begin{array}{l}\text { n-G1. } \\
\text { Kontrol }\end{array}$ & & 0,4294 & 0,20133 & 0,130 & 0,204 & 1.115 & 0,166 \\
\hline \multirow{2}{*}{2} & $\begin{array}{l}\text { n-G2. } \\
\text { Eksperimen }\end{array}$ & & 0,5261 & 0,22582 & 0,167 & $-\mathrm{O}, 130$ & 0,914 & 0,374 \\
\hline & $\begin{array}{l}\text { n-G2. } \\
\text { Kontrol }\end{array}$ & & 0,3724 & 0,24080 & 0,138 & -222 & 1,239 & 0,093 \\
\hline \multirow[b]{2}{*}{3} & $\begin{array}{l}\text { n-G3. } \\
\text { Eksperimen }\end{array}$ & & 0,7217 & 0,21069 & 0,093 & -140 & 0,767 & 0,598 \\
\hline & $\begin{array}{l}\text { n-G3. } \\
\text { Kontrol }\end{array}$ & & 0,5333 & 0,18902 & 0,203 & -130 & 1,114 & 0,167 \\
\hline
\end{tabular}

Sumber: Data diolah SPSS.16.

Berdasarkan tabel 3 tersebut diatas dapat disimpulkan bahwa pada RPP.1 kelas kontrol lebih besar dari kelas eksperimen yang terlihat pada sig.(2-tailed) kontrol $0,166-0,13=$ 0.036 yaitu selisih angka pada eksperimen dan kontrol. Pada RPP.2. pada eksperimen lebih besar dari 
kontrol terlihat pada sig.(2-tailed) 0,374- $0,093=0.281$. Pada RPP 3 . Kelas eksperimen lebih besar dari kontrol karena sig.(2-tailed). 0,598 $0,167=0.813$ adalah selisih antara eksperimen dan kontrol. N-Gain ratarata RPP1 s/d RPP3 ditunjukan pada tabel 4.

Tabel 4 n-Gain rata-rata RPP

\begin{tabular}{|l|l|l|l|}
\hline \multicolumn{2}{|l|}{$\begin{array}{l}\text { Pencapaian n-Gain } \\
\text { rata-rata }\end{array}$} & MEAN & Kriteria \\
\hline \multirow{2}{*}{ RPP.1 } & Eksperimen & 0,3933 & Sedang \\
\cline { 2 - 4 } & Kontrol & 0,4294 & Sedang \\
\hline \multirow{2}{*}{ RPP.2 } & Eksperimen & 0,5261 & Sedang \\
\cline { 2 - 4 } & Kontrol & 0,3724 & Sedang \\
\hline RPP.3 & Eksperimen & 0,7217 & Tinggi \\
\cline { 2 - 4 } & Kontrol & 0,5333 & Sedang \\
\hline
\end{tabular}

Sumber.Data diolah SPSS.16.

Berdasarkan tabel 4 menunjukkan bahwa rata-rata tingkat pemahaman konsep pada setiap RPP adalah sedang. Hal ini disebabkan karena model pembelajaran yang hanya berpusat pada peserta didik sehingga waktu untuk menjelaskan konsep yang mewakili 20 nomor sangat sedikit mengingat waktu dalam proses pembelajaran telah ditetapkan sesuai jadwal yang ada di sekolah. Capaian nGain rata-rata rendah namun itu hanya diukur dari aspek kognitifnya saja.

Angker Model Pembelajaran Kooperatif Tipe Group Investigation (GI)

Berdasarkan analisis angket model pembelajaran maka peneliti menghitung rata-rata eksperimen dan kontrol sebagaimana dituangkan dalam tabel 5 sebagai berikut :

Tabel.5 Rata-rata tanggapan peserta didik tentang model pembelajaran kelas eksperimen dan kontrol.

\begin{tabular}{|l|l|l|l|l|}
\hline \multicolumn{5}{|c|}{ Rata-rata Eksperimen dan Kontrol } \\
\hline $\mathbf{5 6 \%}$ & $\mathbf{4 1 , 2 5 \%}$ & $\mathbf{2 , 7 5} \%$ & $\mathbf{0} \%$ & $\mathbf{1 0 0} \%$ \\
\hline
\end{tabular}

Sumber : data diolah menggunakan Exel.

Berdasarkan tabel 5 menunjukkan bahwa tanggapan peserta didik secara keseluruhan mengenai model pembelajaran kooperatif tipe group investigation (GI) dengan kategori sangat setuju $(\mathrm{SS})=56 \%$, dan Setuju $=41,25 \%$, Tidak setuju $=2,75$ $\%$, Sangat tidak setuju $=0 \%$. Dengan demikian, maka dapat dituangkan pada diagram piechart pada gambar 6 .

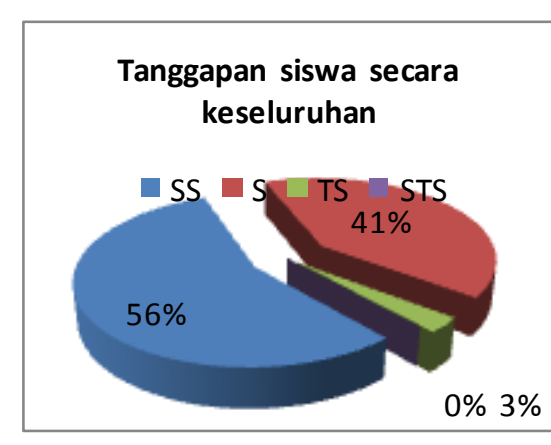

Gambar.6. Diagram Piechart. Tanggapan peserta didik keseluruhan Berdasarkan gambar 6 bahwa penerapan model pembelajaran kooperatif tipe group investigation (GI) sangat cocok untuk membangkitkan semangat belajar peserta didik dengan model penilaian yang tidak saja 
mengarah pada aspek kognitif tetapi juga pada aspek psikomotorik. Model pembelajaran tipe investigasi berpusat pada peserta didik danmelakukan suatu kegiatan berdasarkan teori-teori group investigation dalam suatu kelompok yang heterogen.

Hubungan korelasi antara model pembelajaran tipe group investigation (GI) hasil belajar kimia pada materi polimer peserta didik kelas XII SMA Katholik Sibolga. Dari hasil perhitunganndiperoleh dengan nilai $r$ hitung $=0,316$. Ini menunjukkan bahwa $\mathrm{r}<0,361$ pada $\mathrm{r}$ table, maka dapat disimpulkan bahwa ada hubungan linier yang masuk dalam kategori rendah sesuai dengan hasil penelitian dari Indrawati Malino dan Siregar $\mathrm{T}$ (2013 hal 37) bahwa model pembelajaran tipe jigsau terhadap hasil belajar kimia pada materi Penerapan Model Pembelajaran Tipe Jigsaw Terhadap Motivasi Dan Hasil Belajar Kimia Pada Materi Hidrokarbon Siswa Kelas X SMA Kristen Wamena dapat mempengaruhi hasil belajar peserta didik

\section{SIMPULAN DAN SARAN}

Terdapat hubungan yang signifikan antara model pembelajaran tipe investigasi grup (GI) hasil belajar kimia pada materi polimer peserta didik kelas XII IPA SMA Katolik Sibolga sebesar 0,361 .

\section{SARAN}

Model pembelajaran kooperatif type Group Investigation (GI) dapat digunakan untuk mata pelajaran kimia.

\section{DAFTAR PUSTAKA}

Indrawati Malino dan Siregar T, 2013 Penerapan Model Pembelajaran Tipe Jigsaw Terhadap Motivasi dan Hasil Belajar Kimia Pada Materi Hidrokarbon Siswa Kelas X SMA Kristen Wamena, Jurnal Ilmu Pendidikan Indonesia, 1(3)29-38

Peraturan Menteri Pendidikan dan Kebudayaan Republik Indonesia Nomor 59 Tahun 2014 tentang Kurikulum $2013 \quad$ Sekolah Menengah Atas/Madrasah Aliyah. Sugiyono, 2013. Metode Penelitian Pendidikan (Pendekatan

Kuantitatif, Kualitatif, dan $R$ \& D), Bandung : Alfabeta

Undang-Undang (UU) Nomor 20 Tahun 2003 Tentang perubahan Atas Peraturan Pemerintah Nomor 19 Tahun 2005 Tentang Standar Nasional Pendidikan 